\title{
EDUCAÇÃO GEOGRÁFICA NO COMBATE A NECROPOLÍTICA RACIAL DO CORONAVÍRUS
}

\section{GEOGRAPHICAL EDUCATION IN COMBAT RACIAL CORONAVIRUS NECROPOLITICS}

\section{Dedico essa inquietação a}

Paulo Henrique Menezes da Silva/ Mestre Paulo Kikongo

E a prima Ana Cristina Nóbrega

\author{
Rosemberg Ferracini \\ Doutor em Geografia Humana USP \\ Professor na Universidade Federal do Tocantins, UFT, Porto Nacional \\ rosemberggeo@uft.edu.br
}

\begin{abstract}
RESUMO
Este texto tem como objetivo demonstrar que o racismo estrutural contribui para a espacialização do coronavírus na sociedade brasileira. O diálogo passa por estudos de dados do Ministério da Saúde e do IBGE -Instituto Brasileiro Geográfico e Estatísticorelacionados às escalas espaciais e temporais dos conceitos de branquitude e raça, gênero e classe. Conclui-se que a ausência de políticas públicas afeta diretamente a população pobre e negra do país. Diante dessas problematizações, espera-se alcançar professores e alunos de geografia nos diferentes níveis para uma luta de equidade racial na saúde e da geografia médica.
\end{abstract}

Palavras chaves: racismo estrutural. coronavírus e educação geográfica.

\begin{abstract}
This text aims to demonstrate structural racismo contributes to the spatialization of coronavírus in brazilian society. The dialogue goes through data studis of the Ministry of Health and IBGE -Braziliab Geographic and Statistical Institute- relating to spatial and temporal scales in the concepts of whiteness and race, gender and class. It is concluded that the absence of public polcies directly affects the country's poor and black population. Faced with the problematiza ions, it is expected to reach teachers and students of geography at diferente levels for a fight for racial equity health and medical geography.
\end{abstract}

Keywords: structural racismo. COVID-19. Geographic education and public policy.

\section{INTRODUÇÃO}

O ensaio que se segue é um recorte preliminar do projeto de pesquisa em andamento Educação Geográfica e Acesso à saúde, desenvolvido na Universidade Federal do Tocantins com início em janeiro de 2020. Neste texto, vou problematizar a espacialização do coronavírus no racismo estrutural do território brasileiro. A reflexão está direcionada aos professores de geografia da educação básica, fundamental, média e ao nível superior e visa debater a pandemia tendo em vista as questões étnicoraciais. Advogo com (RIBEIRO, 2019, p. 02) que "falta incluir o espaço escolar no debate do SUS. O espaço escolar (regular e formal) ainda não dialoga com o SUS". Reforço a necessidade de pensar as questões médicas para a formação docente cidadã, se comunicando com o sistema de saúde. Para tal, é simples entender a proximidade entre ciências sociais e as ciências médicas. Estou dizendo da relação entre moradia e tuberculose, água tratada e disenteria, mortalidade e esgoto, lixo urbano e leptospirose, saneamento e expectativa de vida, rendimento e escolaridade ou natalidade. Tais indicadores nos fazem pensar a geografia e a sua relevância social e racial.

Recebido em: 05/05/2020

Aceito para publicação em: 26/05/2020. 
Registrado meu compromisso com a formação de professores atuantes e críticos, nada melhor que, em tempos de pandemia, pensar na espacialização do coronavírus e refletir sobre o papel da geografia para além da sala de aula e em nossas vidas. Minha proposição é que através da realidade professores, em contexto escolar e acadêmico, contribuam para a medidas antirracistas que resolvam o impacto da doença na sociedade por consequente no sistema de saúde. A partir de ações e reflexões, que ajude a construir e implementar políticas públicas que amparem a população atingida, em particular a população negra. Que atue no combate a Necropolítica. MBEMBE 2008, denomina de Necropolítica, as ações ou omissões do Estado, determinando quem deve viver ou morrer, uma política de extermínio para controle da população. Nessa mesma linha de pensamento, proponho a comunidade acadêmica e escolar da Geografia aprofundarmos o debate na Geografia da Saúde em Equidade Racial. Essa redação ganha força a partir da leitura dos dados levantados pelo grupo de pesquisa 'Geógrafos para Saúde', coordenado pelo professor Dr. Raul Borges Guimarães. O grupo contém pesquisadores de diversas instituições brasileiras e internacionais que estão mapeando e debatendo a espacialização do coronavírus. Também me baseei em leitura dos dados do IBGE Instituto Brasileiro Geográfico e Estatístico - no estudo dos Boletins Epidemiológicos sobre o coronavírus apresentados pelo Ministério da Saúde dentre outros. Além disso, minha discussão foi impulsionada pelas conversas com o especialista em saúde da população negra, o professor Altair Lira, antropólogo e sanitarista formado pela Universidade Federal da Bahia.

No início do texto, contextualizarei o tema dos privilégios da racialidade branca e as teorias geográficas coloniais, pensando sobre a omissão ou negação desses discursos diante da realidade presente na sociedade. A partir de dados oficiais em tabelas e gráficos, o ensaio problematiza e explica por que a maioria das vítimas do coronavírus no Brasil, Estados Unidos e continente africano é a população negra.

Nessa discussão, defendo também que é preciso pensar nas práticas escolares para além da sala de aula a fim de refletir que elas acontecem nos diferentes espaços como a rua e os trajetos percorridos entre a casa e a praça, estabelecendo relações com outras escalas de ensino. Apoiado nas ideias da psicologia da aprendizagem e social, argumento a necessidade de uma atividade crítica que rompa com o silêncio e a omissão da sociedade com relação ao racismo estrutural. Problematizo que, para a mudança do racismo estrutural, é preciso postura e ações antirracistas. Por sua vez, acredito que as Instituições Públicas de Pesquisa devem se comunicar com a escola e propor o debate sobre saúde e temas sociais e raciais contextualizados na sociedade. Nessa linha fico com (FÉLIX; BERNARDELLI, 2011, p.211) ao escrevem na necessidade de fortalecer a relação entre as redes públicas de saúde e de educação, "articular as ações do Sistema Único de Saúde -SUS- às ações das redes de educação básica pública, de forma a ampliar o alcance e o impacto de suas ações relativas aos estudantes e suas famílias". Caminharei no texto com a proposta de uma prática pedagógica antirracista (FERRACINI 2020). Da localidade à totalidade, conclamo aos brancos o comprometimento no combate ao racismo estrutural.

\section{OS (DES)CAMINHOS DO COVID-19}

De início, trago para a reflexão o dispositivo analítico da branquitude. A branquitude, em nossa sociedade, está relacionada ao mais alto grau da hierarquia racial, ao grupo étnico-racial branco, que, há séculos, se beneficia de privilégios simbólicos, materiais, políticos, econômicos, culturais dentre outros. Para (Müller e Cardoso, 2017, pp.13-18), a branquitude proporciona as alteridades raciais, reproduz o colonialismo epistemológico e é um símbolo da dominação. No entanto, no interior da discussão sobre essa pertença étnico-racial, surgem pensamentos, contradições e posicionamentos, o que chamamos de branquitude crítica. Dentre os diversos estudos da branquitude crítica, ressalto o do congolês-brasiliano Malomalo (2017). Situado no campo do multiculturalismo libertário, ele historiciza e problematiza o tema, afirmando que "existem brancos aliados, antirracistas que participam na luta da igualdade racial" (p. 260).

Para atuar na luta antirracista, sugerirmos práticas espaciais de ler a realidade e seu entorno. Fazer o aluno entender a proximidade entre as taxas de homicídio e distribuição de renda. A comunidade escolar precisa aceitar que falar de racismo no Brasil é entender as bases de formação territorial em que ele foi construído. Esse debate passa pelas ideologias geográficas de contextos políticos, econômicos e culturais. De acordo com (MORAES, 1988, p.15), as práticas humanas estão carregadas de consciências espaciais via narrativas como produtos históricos. Esses discursos, em sua maioria da racialidade branca, apresentam-se carregados de conteúdos eurocêntricos, dominantes, individuais e meritocráticos que posicionam esse e outros grupos raciais. Segundo 
(FERRACINI 2020), no sistema-mundo colonial, o território africano e sua população foram categorizados como inferiores em contraposição ao branco europeu superior. Por meio do Etnocentrismo científico, Todorov (1993) explicou em Nós e os outros como que, na história dos grupos humanos, foi divulgada a valorização do espaço de superioridade nas diferentes sociedades.

Em estudos clínicos do psiquiatra martinicano Frantz Fanon (FANON, 1968, p.124), ao longo da história, a racialidade branca fortaleceu a diferença racial quando se omitiu ou negou sua existência para a manutenção dos seus privilégios, reforçando (in)diretamente a superioridade racial branca. Destaco que, em suas ações, o branco pode afirmar ou negar (in)diretamente o sistema da mentalidade da "casa-grande e senzala". Baseada em fundamentos da teoria da aprendizagem, a psicanalista Maria Aparecida Silva Bento (2002) defende que existem "pactos narcísicos no racismo" entre brancos quando estes omitem ou silenciam a discriminação racial em função de alguns interesses. Esses pactos passam pela negação e medo da perda dos privilégios. Assim, afirmamos que o racismo é um sistema de opressão que nega e silencia vozes negras, por isso são necessárias mudanças dos brancos para grandes transformações para o combate a essa realidade.

Considero como racismo estrutural as insuficiências de sistemas básicos na cidade, em particular nas periferias. Em leitura de Sodré, apreende-se que, desde a colônia, na condição de ex-escravo, "o negro era excluído dos privilégios da cidadania", intensificando-se "as regras de segregação territorial, tradicionais na organização dos espaços brasileiros" (SODRÉ, 1988, p. 39). Não por acaso, a comunidade negra foi excluída, sofrendo com a problemática histórica e social, em decorrência do escravismo e da ausência de políticas públicas básicas, o que fortaleceu a injustiça social, a discriminação racial no cotidiano, gerando o racismo estrutural.

Existem alguns movimentos contrários ao racismo estrutural, como o já elencado movimento de brancos antirracistas, a branquitude crítica. Retomo Malomalo (2017, p. 272), quando escreve a respeito do compromisso antirracista branco na vigilância epistemológica e ética. Para que tal atitude se efetive, é preciso uma leitura reflexiva e crítica diante da realidade a fim do enfrentamento dos condicionantes raciais formados no território brasileiro. Precisamos lutar por uma diferente valorização econômica do espaço, pelo respeito de outras ideologias culturais e pelas mudanças nas políticas territoriais para que o racismo estrutural acabe.

Diante desse compromisso, minha inquietação se acirrou quando, nas primeiras semanas da pandemia no Brasil, o Ministério de Ciência, Tecnologia, Inovações e Comunicações (MCTIC), em meio a olhares tortuosos, reorganizou suas ações e publicou a Portaria 1.329, em 27/03, com o seguinte título: Precisamos das Ciências Sociais e Humanas para compreender e enfrentar a pandemia de Covid-19. Paradoxalmente, o Ministério não traduzia, na Portaria, em atos concretos o enfrentamento da pandemia propondo financiamentos de pesquisas para o combate ao coronavírus. Muito pelo contrário, o governo federal cortou diferentes bolsas, persegue a Universidade e a desmerece em rede nacional. Como já sabido, a saúde e o enfrentamento do COVID-19 não podem ser pensados somente a partir de fatores biológicos, mas também por questões sociais e econômicas.

O Brasil possui uma população negra que, em sua maioria, é excluída dos dados estatísticos das disparidades sociais. Essa realidade está presente no boletim publicado pelo IBGE em novembro de 2019, "Desigualdades sociais por cor ou raça no Brasil". Leiamos na Figura 1)

Com os dados do (IBGE 2019) acima é preciso sair da zona de conforto e exercitar que com o público escolar, de 2012 a 2017, a taxa de homicídios da população negra ou parda teve o aumento de $10 \%$ em relação à branca. Essa realidade afeta a base familiar, escolaridade e o trabalho conforme os indicadores os dados do IBGE de 2019. Racismo estrutural que continua presente nas diversas escalas da sociedade nos anos de 2020. De acordo com os dados publicados da (OXFAN, 217, p. 06), "os $5 \%$ mais ricos detêm a mesma fatia de renda que os demais $95 \%$ " no Brasil. Baseados nos dados da Oxfan, afirmamos que o coronavírus não é democrático, porque ele atinge a população mais vulnerável.

Em tempos de pandemia provocada pela espacialização do coronavírus, o Instituto Identidades do Brasil (ID_BR), em parceria com outras entidades, realizou um estudo em 19 estados e Distrito Federal demonstrando como a população feminina negra é atingida pelo desemprego na sociedade brasileira. O estudo é importante porque nos ajuda a refletir sobre as práticas informais escolares que significa a quarentena para as mulheres negras. Na mesma linha, nos dados levantados pelo IPEA - 
Instituto de Pesquisa Econômica Aplicada em 2018-, o índice de desemprego das mulheres negras era $50 \%$ maior do que das mulheres brancas (FOGUEL E FRANCA, p. 73).

\section{Figura 1)}

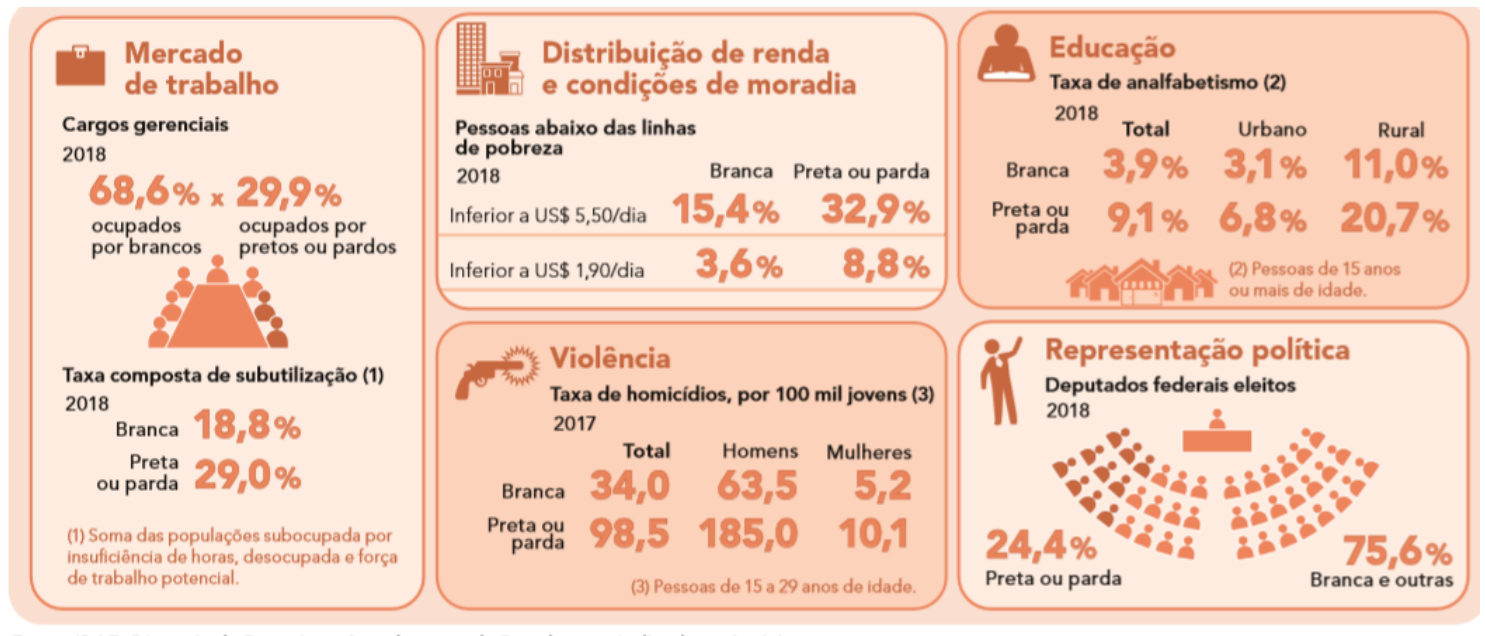

Fonte: IBGE, Diretoria de Pesquisas, Coordenação de População e Indicadores Sociais.

Em pesquisa no site do Ministério da Saúde, encontramos um levantamento estatístico feito pelo Instituto de Estudos para Políticas de Saúde (leps) sobre a distribuição regional dos leitos de UTI, ventiladores e respiradores, cruzando os dados das sociais com as causas de mortalidade da população. $O$ estudo buscou identificar regiões mais vulneráveis e fazer projeções da capacidade de atendimento da evolução dos casos de coronavírus. Temos, como exemplo, a Figura 2)

Figura 2)

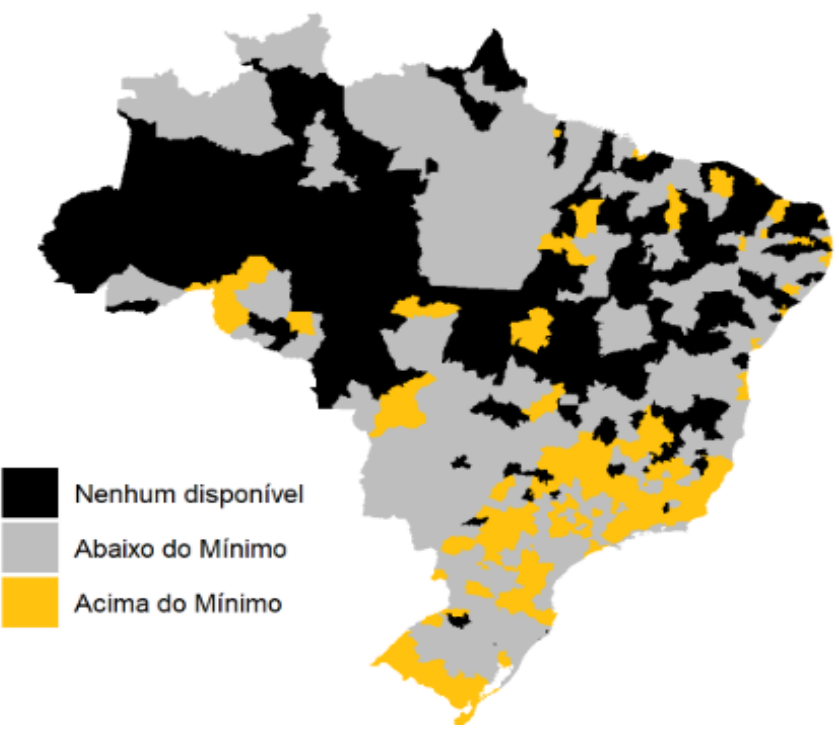

Fonte: Rache, Rocha, Nunes, Spinola, Malik, Massuda (2020). 
Quando lemos o mapa, percebemos o racismo institucional (RI) que, segundo (WERNECK, 2016, p. 541), "é a dimensão mais negligenciada do racismo, desloca-se da dimensão individual e instaura a dimensão estrutural, correspondendo a formas organizativas, políticas, práticas e normas que resultam em tratamentos e resultados desiguais". Digo ser as políticas públicas desiguais entre as partes do território. Uma vez que segundo o Ministério da saúde é desejável o mínimo de 10 leitos a cada 100 mil habitantes. Realidade que traz o aumento da pandemia com a população vulnerável que não possui bases médicas, profissionais de saúde e instituições para se manterem vivos. É o descaso do Estado na ausência de toda e qualquer estrutura social da renda a diagnósticos médicos para tratamento. A Necropolítica na prática, ditando quem vive e quem morre.

Outros dados relativos aos fatores de vulnerabilidade ao coronavírus podem ser encontrados nas pesquisas desenvolvidas por Luisa Nassif Pires (Levy Economics Institute), Laura Carvalho (Universidade de São Paulo) e Laura de Lima Xavier (Harvard Medical School). Segundo as pesquisadoras, existem variáveis que tornam as populações de baixa renda mais expostas à contaminação pelo novo coronavírus, "tais como o uso de transporte público, o número maior de moradores por domicílio, a falta de acesso a saneamento básico, a acesso a médicos e a dificuldade de manter o isolamento social sem perda excessiva de renda ou do emprego", (p. 02). Esse fato pode ser encontrado no Boletim "Relação Anual de Informações Sociais" de 2018, divulgado pelo Ministério da Economia. Entre 1985 a 2018, existiram no território brasileiro 46.631 .115 empregos formais, com variação absoluta e ou relativa, sendo que os piores salários eram pagos majoritariamente aos trabalhadores negros ${ }^{2}$. A população negra, por isso, não pode evitar ou diminuir os riscos ao coronavírus, pois necessita de renda para sobreviver.

Diante desse conjunto de fatos, trago como problematização e a sugestão de ensino, pesquisa e extensão o tema da branquitude crítica enquanto elemento fundamental para o combate ao racismo estrutural e ao coronavírus. Como também problematizações escolares que abordem a branquitude crítica que reflita sobre as condições de vida em que vive a população negra. Nesse sentido, uma reflexão que os professores devem desenvolver quanto ao meio-técnico-cientifico-informacional é a respeito do número de leitos de UTI - Unidade de Terapia Intensiva- para a população que possa vir a necessitar de cuidados intensivos. As exigências nesse tipo de tratamento são as do mais alto campo profissional especializado, com a necessidade de médicos intensivistas, enfermeiros, fisioterapeutas, técnicos de enfermagem, psicólogas, nutricionistas e demais especialistas. Contudo, de acordo com o site do Ministério da Saúde, $72 \%$ das regiões brasileiras possuem o número de leitos de UTI por 100 mil habitantes inferior ao mínimo necessário. Qual nome podemos dar a essa realidade? Temos um Sistema Único de Saúde (SUS) insuficiente, ineficiente e precarizado pelo atual governo.

Escrevo da realidade que faz parte da criança, jovem e adolescente é quando ele percebe a discrepância nos serviços básicos nos leva a refletir sobre a Necropolítica que atinge a população negra, fazendo com que não possua condições mínimas de sobrevivência. Como já salientado anteriormente, professores devem propor o exercício de entender a Geografia nos diferentes espaços vividos. Digo ser importante que a branquitude reveja o seu papel histórico, reflita e pense como o racismo se organizou, e nas bases que se sustenta e que é possível a sua desconstrução. Em leitura dos dados do (IBGE 2019), é nítido que essa população pobre constitui uma parte significativa da sociedade, sem contarmos os que se encontram em situação de extrema pobreza. Portanto, há uma falta de acesso à água tratada, esgoto, energia, educação e demais serviços básicos. Se queremos conter as escalas entre ricos e pobres e combater o racismo estrutural, deveria ser prioridade do governo, do estado e do município investimento a fim da diminuição das distâncias entre viver ou morrer. Fato já sabido são que as doenças, em sua maioria, não são democráticas. Elas atingem mais pessoas de classe, gênero e raça específicos. O coronavírus não escolhe raça, mas a ausência de políticas públicas nas periferias e a falta de condições sanitárias e de moradias nos bairros pobres proporcionam que as pessoas expostas a essas dificuldades estejam igualmente mais vulneráveis à pandemia.

Em meados de janeiro de 2020, os trabalhos da geógrafa inglesa Melissa Leach ${ }^{3}$ foram lembrados em publicação na Nature por causa da sua luta contra o Ebola na África Ocidental. Para a estudiosa, saúde pública e questões sociais andam juntas. Interpretamos que a saúde melhora quando ocorre justiça social no combate à pobreza. Por isso, podemos dizer que a pandemia tem cor, classe e

\footnotetext{
2 Fonte: http://www.rais.gov.br/sitio/index.jsf

3 Diretora do Instituto de Estudos do Desenvolvimento (IDS). O texto a que nos referimos é Infectious disease: Tough choices to reduce Ebola transmission. Nature News, Publisher: Springer Nature. Date: Nov 6, 2014.

DOl:http://dx.doi.org/10.14393/Hygeia0054459 $\quad$ Hygeia Edição Especial: Covid-19, Jun./2020 p.211 - 220, pág.215
} 
gênero. A ausência do poder público na falta de oportunidade, emprego e saúde torna o vírus uma realidade para os mais vulneráveis. A possibilidade de acesso a banheiro, renda e alimentação básica interferem diretamente na saúde da população.

Um exemplo da nossa explanação são as informações presentes no livro da professora Tereza Campello, em 2017, com o título "Faces da desigualdade no Brasil: um olhar para os que ficam para trás". No capítulo "Acesso a políticas universais na busca por equidade", há o seguinte dado:

Negros e negras representam mais da metade da população brasileira em termos numéricos. São reconhecidos os altos níveis de exclusão de acesso a direitos que a população negra é historicamente submetida. A perversidade da desigualdade que mais marca a cisão da sociedade é expressa em um dado gigantesco: entre os pobres, mais de $70 \%$ são negros. (CAMPELO, 2017, p. 47)

As distâncias entre brancos e negros, ricos e pobres estão presentes em dados, tabelas, textos e gráficos por toda a obra de Campello (2017). Escolhemos esse trecho como subsídio para que os diferentes níveis de professores possam problematizar e demonstrar aos seus alunos como classe e raça têm uma organização histórica no território brasileiro. Em um país de pobres e negros, os maiores números de mortes são de pessoas pobres e negras, a Necropolítica de (MBEMBE, 2008). Nesse sentido, acreditamos que, para acabar com a disparidade racial, cabe à elite e à classe média branca o desafio comum de combater o racismo disfarçado em nossa sociedade. $O$ descaso de corpos negros e pobres não pode continuar sendo algo menor diante da economia do país.

$\mathrm{Na}$ condição de aluno, professor, pai ou mãe como irei praticar a recomendação de isolamento para conter o coronavírus? O governo desconhece a minha realidade e de parte significativa da população que mora em barracos amontoados em comunidades, favelas e periferia das cidades. Nessas moradias, famílias vivem juntas com avós, filhos, mães, pais, primos e demais parentes. De acordo com dados de (CAMPELLO, 2017, p. 29), o acesso ao esgoto e água tratada chega somente aos $5 \%$ dos mais pobres do país. Para essa população, tudo indica que a mortalidade infantil será alta e a expectativa de vida, baixa. Nesse aspecto, afirmamos a importância de ler a realidade com os olhos espaciais nas práticas informais como a rua. Entender que a alteridade de classe gera uma disparidade racial, a Necropolítica. Minha meta como professor é dar visibilidade ao descaso com a população negra através da realidade, de pesquisas científicas e chamar os brancos ao debate. Se queremos construir um país igualitário, essa pandemia tem algo a ensinar: a luta pelo fim das desigualdades raciais e de classe como exemplificado na Figura 3):

Figura 3)

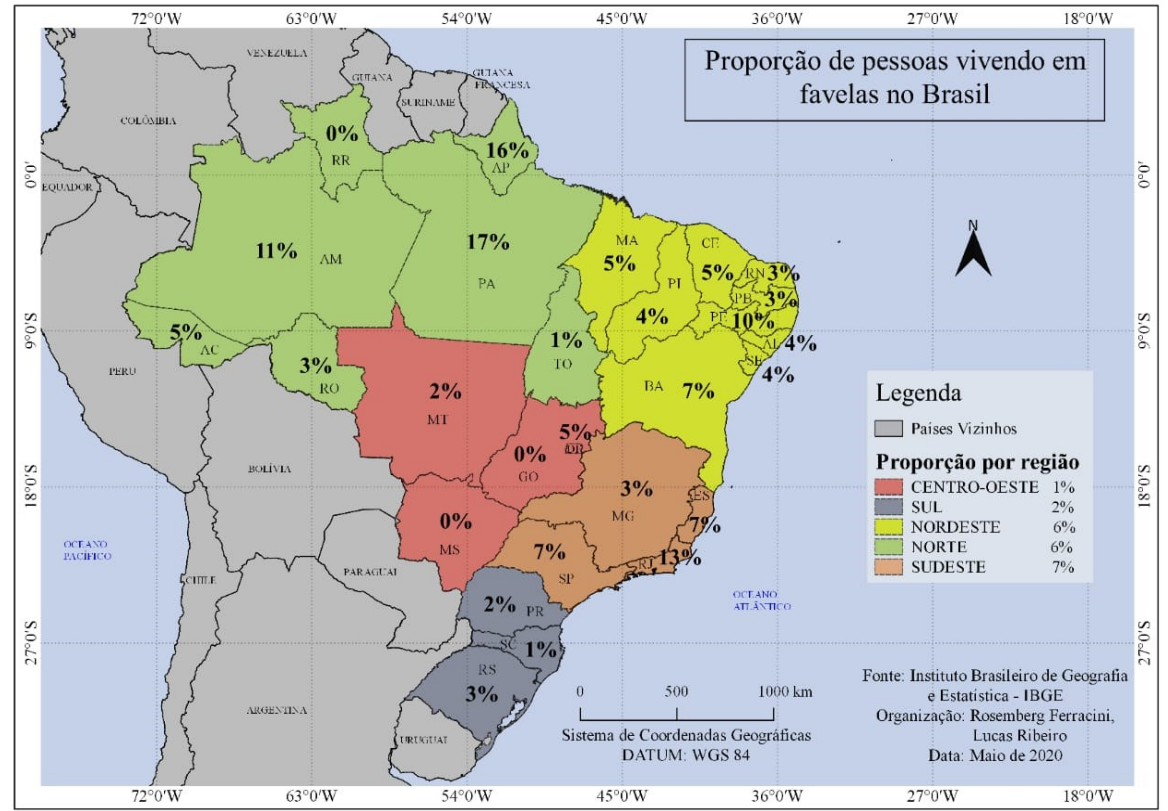


A realidade está posta na rua e seus diversos trajetos. De acordo com os últimos dados do IBGE, no Brasil, aproximadamente 13,6 milhões de pessoas moram em favelas. Os estados com maior proporção de pessoas vivendo nessas moradias são Pará com 17\%, Amapá com 16\%, Rio de Janeiro com 13\%, Amazonas com 11\% e Pernambuco com 10\%. O estudo "Raça, Classe e Gênero. Unidade na diversidade" realizado pelo CONEN 2020 - Coordenação Nacional de Entidades Negras nos ajuda a pensar a respeito do racismo estrutural da realidade brasileira:

$97 \%$ dos moradores de favelas já mudaram sua rotina por causa do coronavírus, $47 \%$ dos moradores das favelas são autônomos, 19\% têm carteira assinada, 8 em cada 10 famílias afirmam que sua renda vai diminuir graças ao novo coronavírus, $63 \%$ afirmam que a alimentação seria prejudicada se precisassem permanecer em suas casas, se perderem a renda, $72 \%$ não conseguem manter o padrão de vida por tempo algum.

Sabendo das proximidades entre ciências médicas e humanas, os dados e informações propiciam alunos a pensar e problematizar a sua realidade. Esses irão relacionar e questionar o porquê nas áreas periféricas, o acesso a tratamento e diagnósticos é mais limitado? Ainda segundo o IBGE: "Em 2018, verificou-se maior proporção da população preta ou parda residindo em domicílios sem coleta de lixo, sem abastecimento de água por rede geral, e sem esgotamento sanitário por rede coletora ou pluvial (42,8\%, contra 26,5\% da população branca)", (IBGE, 2019, p. 05).

Tais dados demonstram como o racismo estrutural e institucional com a população negra interferem diretamente no desenvolvimento de crianças, jovens e adultos no que tange à saúde. A esse respeito, foi somente a partir do dia 10 de abril de 2020 que o Ministério da Saúde passou a inserir os dados raça/cor nas fichas de atendimento médico. Esse fato se deu pela solicitação e exigência da SBMFC (Sociedade Brasileira de Medicina de Família e Comunidade) e da Coalizão Negra por Direitos. As duas entidades pediram que os dados referentes às pessoas infectadas pelo recorte cor/raça fossem divulgados segundo o direito à Lei de Acesso à informação. Em Carta ao Ministério da Saúde sobre a informação raça/cor nos sistemas de informação da Covid-19, a Abrasco - Associação Brasileira de Saúde Coletiva- solicitou a "Divulgação de dados desagregados por raça/cor nos painéis de monitoramento, boletins epidemiológicos, notas técnicas, e demais documentos oficiais relativos à Covid-19". No Boletim Epidemiológico do Ministério da Saúde com o recorte racial, temos que, antes do COVID-19, eram baixos os registros de Síndrome Respiratória Aguda Grave (SRAG), havendo um aumento desse número após a pandemia. Além disso, há baixo índice de testagem para 0 coronavírus. Na Figura 4), observamos as hospitalizações causadas pela (SRAG) e o aumento posterior em 2020:

Figura 4)

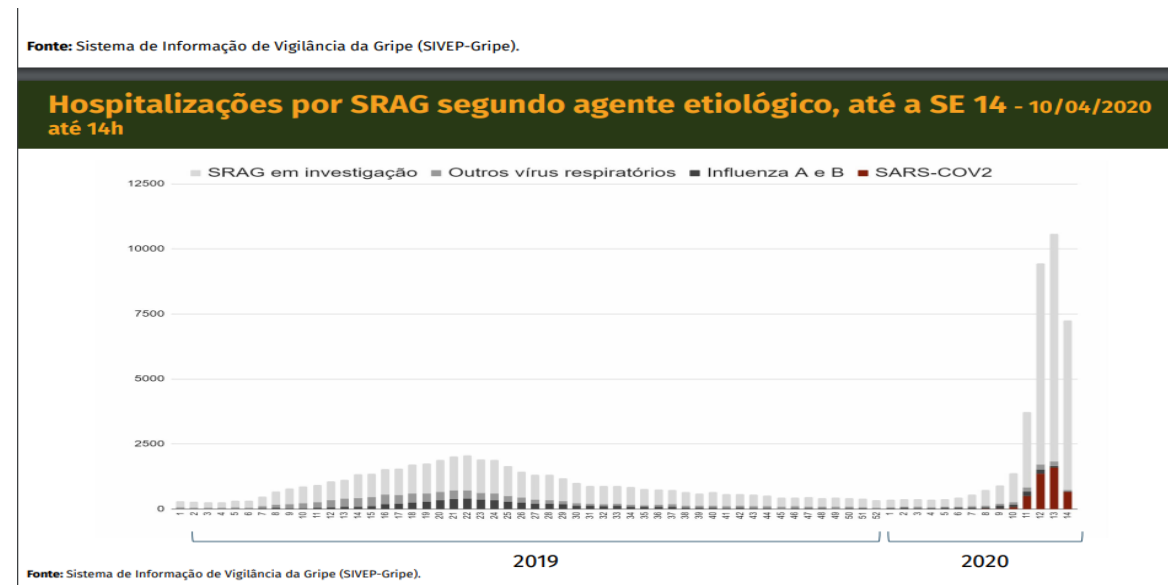

A comunidade escolar tem que questionar sobre quais populações estão sendo testadas para conseguirmos saber dos dados relacionados à população negra. Além desse problema de informação, existe também o baixo interesse governamental em atender às populações da periferia. Não há nada delineado de maneira específica para a população que não possui condições mínimas de moradia, em que o processo de urbanização foi e é excludente, o que, por sua vez, interfere na DOl:http://dx.doi.org/10.14393/Hygeia0054459 $\quad$ Hygeia Edição Especial: Covid-19, Jun./2020 p.211 - 220, pág.217 
geração e propagação de doenças respiratórias. Se lembrarmos do sucateamento do SUS, o único sistema que possibilita testes, internações, tratamentos e demais hospitalização para os mais pobres, vemos a situação dramática das populações negras.

Em leitura do site da Sociedade Brasileira de Medicina de Família e Comunidade, há a informação de que $67 \%$ dos brasileiros utilizam e dependem unicamente do Sistema Único de Saúde (SUS), sendo essa população composta, em sua maioria, por negros. Se pensarmos também nas outras doenças que, por uma questão socioeconômica podem acometer essa população como a diabete, tuberculose, anemia falciforme, hipertensão e doenças renais crônicas, o quadro favoreceria a propagação e a evolução dos quadros do Covid-194. Infelizmente, as políticas públicas não são pensadas tendo em vista esse quadro de vulnerabilidade das populações negras. Essas pessoas eram atendidas pela Política Nacional de Saúde Integral da População Negra e o enfrentamento do Racismo Institucional - PNSIPN -, mas esse programa vem sendo desarticulado desde o Golpe de 2016. A PNSIPN tem como objetivo "promover a saúde integral da população negra, priorizando a redução das desigualdades étnico-raciais, o combate ao racismo e discriminação nas instituições e serviços do Sistema Único de Saúde (SUS)" (BRASIL, 2013, p.19).

\section{UMA LUTA LOCAL E GLOBAL}

A Geopolítica está em toda parte, dos jornais impressos e nas mídias digitais, não por acaso o racismo estrutural está presente nos Estados Unidos. Segundo a Brookings Institution, organização de políticas públicas com sede em Washington, o mapeamento da desigualdade racial em meio ao COVID-19 mostra como a pandemia é avassaladora contra a população afro-americana. Como no Brasil e nos EUA, a hipertensão arterial e diabetes são fatores de risco para formas mais graves da infecção e são condições de alta incidência em pessoas negras. A médica epidemiologista Sharrelle Barber, professora na Universidade Drexel, em entrevista ao Jornal The New York Times" ${ }^{5}$, registra as "disparidades sociais e econômicas estruturais entre negros e brancos", explicando que "nos EUA, uma grande parte da população negra vive em áreas onde faltam oportunidades de trabalho, a habitação é instável e é difícil encontrar comida saudável nos mercados". Em se tratando da população negra, temos inúmeras variáveis que nos permitem constituir uma escala de valores para conceituar quem pode viver ou morrer.

Essa informação nos instiga analisar as relações de poder entre diversos grupos "como espaço de pertencimento dos sujeitos e de superposição de diversos tipos de interesse (políticos, econômicos, culturais)", (GUIMARÃES, 2015, p. 89). O isolamento é uma condição de classe, cor e gênero. Qual é a cor e a classe dos funcionários que desenvolvem serviços em supermercados, padarias, transporte, limpeza, manutenção e demais trabalhos? Assim como no Brasil, a população afro-americana precisa de reparações com políticas para saúde, educação e moradia a fim de combater o racismo estrutural

De acordo com o trio de pesquisadores de políticas públicas Andre M. Perry, Carl Romer e David Harshbarger, as comunidades negras nos EUA estão enfrentando uma das mais altas taxas de mortalidade do coronavírus. A letalidade devido ao coronavírus é alta nos bairros onde a maioria da população é negra. Segundo esses pesquisadores, "a desvalorização histórica e sistêmica da habitação, a injustiça econômica, a discriminação nos cuidados de saúde" são "condições que aumentam as taxas de óbitos, especialmente durante essa pandemia". Fato é que as famílias brancas americanas possuem 10 vezes maior riqueza e até mesmo os acadêmicos brancos possuem 7 vezes mais renda do que os negros. Esses e demais fatos refletem na qualidade e expectativa de vida. O racismo estrutural, ainda, é gritante quando o governo permite o perdão das dívidas universitárias de brancos e estende os empréstimos dos negros, gerando abandono escolar e dependência.

Outro exemplo ocorre em Chicago onde 30\% da população é negra e 70\% de mortes por COVID-19 são de pessoas negras. No estado da Louisiana, elas são $70 \%$ de todas as mortes, com $33 \%$ da população do estado negra. No Alabama, negros são $44 \%$ das mortes e $26 \%$ do total de habitantes. Essa realidade foi constatada diretamente pelo prefeito de Londres, Sadiq Khan, em texto do dia 19 de abril publicado no jornal The Guardian: "o racismo estrutural é a causa de mais mortes por COVID-19 entre minorias". Esses números, segundo o prefeito, podem ser pensados dentro da perspectiva de vulnerabilidade da saúde e

\footnotetext{
4 Para aprofundar, ver LIRA, A.S. Análise da assistência ofertada às gestantes com Doença Falciforme, em Salvador-BA: o racismo nas tramas e enredos das redes do SUS. Dissertação Mestrado- Instituto de Saúde Coletiva. Universidade Federal da Bahia. - Salvador: 2015, 84 p.
}

${ }^{5}$ Black Americans Face Alarming Rates of Coronavirus Infection in Some States, https://www.nytimes.com/2020/04/07/us/coronavirus-race.html

DOl:http://dx.doi.org/10.14393/Hygeia0054459 $\quad$ Hygeia $\quad$ Edição Especial: Covid-19, Jun./2020 p.211 - 220, pág.218


falta de emprego dessas populações ${ }^{6}$. Em outra publicação, a Revista Big Easy, de Nova Orleans, Asad El Malik assina o artigo "A cor de uma pandemia: COVID-19, pobreza e raça em Nova Orleans". No texto, o autor contextualiza historicamente o racismo institucional no sistema de saúde, tendo em vista as condições de maior letalidade do vírus como asma, diabetes e hipertensão. Faz parte do alto índice de contaminação as condições das casas em que vivem várias famílias, o que está relacionado aos altos custo da habitação. Na mesma pesquisa, encontramos alguns elementos que demonstram a diferença de classe relacionada à raça, salário e pobreza. Os coeficientes são: custos de moradia, o acesso à internet, famílias com patrimônio, acesso a veículos, patrimônio zero dentre outros. Segundo o relatório, $32 \%$ da população negra de Nova Orleans vivem em extrema pobreza em comparação aos $10 \%$ da família brancas.

Com esses dados, observa-se que o genocídio começa em solo africano com a partilha da África e o processo de escravidão perdurando nas dependências econômicas perversas globais até os dias. Foram 350 anos de escravismo da população negra, que sofreu a violência do descaso com sua saúde e maustratos. Para agravar essa situação, a pesquisa recém-publicada por Monié "Coronavírus/COVID-19: difusão espacial, impactos e desafios" na África Subsaariana (2020, pp. 22) nos expõe outro dado preocupante: "Num continente onde entre 70 e $90 \%$ dos medicamentos são importados e frequentemente caros, o baixo poder aquisitivo da maioria da população estimula o recurso a produtos falsificados, produzidos localmente ou importados". A relação entre a vida e o acesso à saúde recebe forte influência da geopolítica do sistema de saúde tributário, podendo ser vista também como uma dívida histórica de exploração comercial do Fundo Monetário Internacional - FMI - e - G20 - os 20 países mais ricos do mundo.

\section{CONCLUSÃO}

A pandemia do coronavírus escancara o descaso com a população negra, com a classe trabalhadora e com as mulheres que estão, em sua maioria, nessa linha de frente da pandemia. As mortes pelo COVID19 têm demonstrado as enormes alteridades psíquicas raciais, de classe e gênero no Brasil e no mundo. Essas diferenças se refletem na moradia, no acesso à água tratada e esgoto, na carência de um sistema de saúde pública, na concentração de renda, enfim nas diferentes faces do racismo estrutural e institucional.

No decorrer do texto, explicamos que esse tipo de racismo atinge, de maneira geral, a população negra, seja pela omissão, negligência, invisibilidade, falta de planejamento das políticas públicas e pela inviabilização do SUS. No decorrer da discussão, observamos os boletins publicados pelo Ministério da Saúde que não traziam atualização dos dados no que se refere a idade, gênero, classe e raça. As análises presentes neles são superficiais e sem contextualização da realidade brasileira. Percebe-se no boletim do dia 26 de abril um amontoado de dados jogados em formato pdf sem levar em consideração os estados e municípios que, a cada dia, estão apresentando mais números de infectados. Diante da triste realidade, infelizmente teremos um alto número de mortes pela falta de acesso ao SUS e pela baixa qualidade nos equipamentos ofertados por ele. Por isso, a sociedade brasileira necessita de políticas públicas sérias que atendam raça, classe e gênero.

Creio ser necessário pensar em políticas públicas de enfrentamento efetivo das escalas temporais, espaciais e raciais no Brasil. É urgente o fim da Necropolítica (MBEMBE, 2008). Como registrado no início do texto, sugiro que os $5 \%$ mais ricos compartilham seus privilégios. O sujeito branco precisa entender e aceitar que a branquitude faz parte de um conjunto de normas, ações, leis de privilégios que não alcançam a população negra e, para mudanças, é preciso atitudes. Advogo com (FERRACINI, 2020, p.18) para quem a "geografia deve proporcionar justiça e igualdade social e racial".

Diante do conjunto já redigido, retomo algumas propostas elencadas na PNSIPN, a fim de apontar ações para acabar com o racismo estrutural: fomentar a realização de estudos e pesquisas sobre racismo e saúde de Geografias Negras; monitorar e avaliar os indicadores e as metas pactuados para a promoção da saúde da população negra, visando reduzir as iniquidades macrorregionais, regionais, estaduais e municipais; monitorar e avaliar as mudanças na cultura institucional a fim de garantir os princípios antirracistas e não-discriminatórios, inserindo a interseccionalidade de classe, gênero e raça como aspecto importante da saúde da população negra. Junto a isso é preciso que o (MCTIC) invista em projetos de pesquisas que contemplem as humanidades e ciências sociais para o combate as disparidades sociais e

\footnotetext{
${ }^{6}$ https://www.theguardian.com/commentisfree/2020/apr/19/bame-dying-coronavirus-sadiq-khanThe Guardian, 19 de abril de 2020.
} 
raciais. Sugiro, por fim, algumas questões que merecem ser investigadas e aprofundadas na Geografia Médica e da Saúde como investimento em pesquisas que contribuam para a formulação de políticas públicas direcionadas aos indicadores sociais e de saúde da população negra brasileira. Essas ações impactarão nas taxas de natalidade, mortalidade, expectativa de vida e escolaridade dessas populações na Luta Antirracista.

\section{BIBLIOGRAFIA}

BRASIL. Ministério da Saúde. Secretaria de Gestão Estratégica e Participativa. Departamento de Apoio à Gestão Participativa. Política Nacional de Saúde Integral da População Negra: uma política para o SUS. Brasília: Editora do Ministério da Saúde, 2. ed. 2013. 36 p.

CARVALHO, Laura, PIRES, Luiza Nassif, XAVIER, Laura de Lima. COVID-19 e desigualdade: a distribuição dos fatores de risco no Brasil. Disponível em https://www.researchgate.net/publication/340452851 COVID-19 e Desigualdade no Brasil

EL MALIK, Asad. Revista Big Easy. Nova Orleans, 28 de março de 2020.

FANON, Frantz. Pele negra, máscaras brancas. Rio de Janeiro: Civilização Brasileira, 1968.

FÉLIX, W.; BERNARDELLI, C. Educação e Promoção da Saúde: Reflexões Sobre os Programas Saúde Na Escola e Saúde Todo Dia. Hygeia - Revista Brasileira de Geografia Médica e da Saúde, v. 7, n. 13, 20 dez. 2011.

FERRACINI, Rosemberg. Aprendendo com a comunidade-terreiro em Palmas-TO Na Luta Antirracista. Revista da Associação Brasileira de Pesquisadores/as Negros/as (ABPN) v. 12, n. Ed. Esp, p. 221-242, abr. 2020. https://doi.org/10.31418/2177-2770.2020.v12.c1.p221-242

Professores e Alunos em Perspectivas Afrodecoloniais: Teorias e Práticas Escolares. Revista África e Africanidades - Ano XII - n. 33, fev. pp.10-26 2020.

FOGUEL Miguel, FRANCA Maíra Penna. A sensibilidade do desemprego às condições da economia para diferentes grupos de trabalhadores, In, Boletim Mercado de Trabalho - Conjuntura e Análise. $N^{\circ} 65$, outubro 2018, pp. 71-79.

GUIMARÃES, Raul B. Saúde: fundamentos de geografia humana. SP: Ed.UNESP, 2015.

IBGE - Estudos e Pesquisas. Desigualdades Sociais por Cor ou Raça no Brasil. Informação Demográfica e Socioeconômica $\cdot$ n.41, 2019.

MALOMALO, Bas'llele. Retrato dos brancos/as antirracistas feito do ponto de vista de uma educação macumbista. In, Branquitude: estudos sobre a identidade branca no branca no Brasil. Müller, Tania e Cardoso, Lourenço. Curitiba: Appris, 2017, pp. 259-276.

MBEMBE, Achille. Necropolítica. N-1dições, São Paulo-SP, 2018.

MONIÉ, Frédéric. A África subsaariana diante da pandemia de Coronavírus/COVID-19: difusão espacial, impactos e desafios, Espaço e Economia [Online], 18, 2020. https://doi.org/10.4000/espacoeconomia.13629

OXFAN. A distância que nos une: um retrato das desigualdades brasileira. 217, 94 p.

RACHE B., ROCHA, R., NUNES, L., SPINOLA, P., MALIK, A. M. e A. MASSUDA (2020). Necessidades de Infraestrutura do SUS em Preparo à COVID-19: Leitos de UTI, Respiradores e Ocupação Hospitalar. Nota Técnica n³. IEPS: São Paulo.

RIBEIRO, E. A. W. EM DEFESA DO SUS. Mais Geografia: Balanço do IX Simpósio Nacional de Geografia Da Saúde. Hygeia - Revista Brasileira de Geografia Médica e da Saúde, v. 15, n. 33, p. 1-7, 21 nov. 2019. https://doi.org/10.14393/Hygeia153351658

SODRÉ, Muniz. O terreiro e a cidade. Petrópolis: Vozes, 1988.

TODOROV, Tzevetan. Nós e os outros. A reflexão Francesa Sobre a Diversidade Humana. Vol.01 RJ: Jorge Zahar Editor, 1993.

WERNECK, Jurema. Racismo institucional e saúde da população negra. Saúde Soc. São Paulo, v.25, n.3, p.535-549, 2016 Sociedade. São Paulo, v.25, n.3, p.535-549. https://doi.org/10.1590/s0104129020162610 